\title{
A SOCIEDADE GLOBAL DE RISCO E A CONSTITUCIONALIZAÇÃO DO PRINCÍPIO DA EQUIDADE INTERGERACIONAL
}

\author{
Luís Marcelo Mendes ${ }^{1}$ \\ Jerônimo Siqueira Tybusch ${ }^{2}$
}

\section{Resumo}

O artigo visa realizar uma projeção sobre o processo de constitucionalização do princípio da equidade intergeracional para consolidar o acesso ao meio ambiente sadio e equilibrado para as gerações presentes e futuras dentro da sociedade global de risco. A pesquisa faz uso do método dedutivo auxiliada por premissas dialéticas para materializar um diagnóstico sobre a problemática proposta. Num primeiro momento, analisar-se-á como a modernidade industrialcapitalista contribui no processo de construção da sociedade global de risco através do desenvolvimento da técnica-ciência e de seus desdobramentos no processo de degradação do natural. Posteriormente, verificar-se-á se a constitucionalização do preceito da equidade

\footnotetext{
${ }^{1}$ Mestre em Direito pela Universidade Federal de Santa Maria na Linha Direitos da Sociobiodiversidade e Sustentabilidade (2015). Especialista em Direito Constitucional Contemporâneo pela Universidade de Passo Fundo (2010). Graduado em Direito pela Universidade Luterana do Brasil (2007). Integrante do Núcleo Docente Estruturante e do Conselho do Curso de Direito da ULBRA Carazinho. Coordenador do Projeto de Pesquisa sobre o impacto socioambiental deflagrado pelo uso excessivo de agrotóxicos na agricultura intensiva nos municípios do COREDE da Região da Produção do Rio Grande do Sul. Coordenador dos Projetos de Extensão do Observatório da Violência e dos Direitos Humanos e do Programa de Enfrentamento às Questões de Gênero. Líder do Grupo de Pesquisa Estado, Sociedade e Direitos Humanos (ULBRA), inscrito no CNPq, com atuação nas Linhas de Pesquisa: Estado Sociedade e Direito; e Efetivação dos Direitos Humanos. Integrante do Grupo de Pesquisa em Direito da Sociobiodiversidade (GPDS), inscrito no CNPq, com atuação na Linha de Pesquisa: Ecologia Política e Direito. No Curso de Direito da ULBRA Carazinho atua como docente nas disciplinas de Filosofia do Direito, História do Direito, Direitos Humanos e Fundamentais, Antropologia e Sociologia Jurídica, Processo Negocial, Direito Internacional, Direito Civil I Parte Geral, Direito Civil V Família, Teoria Geral do Processo, Direito Processual Civil I, Trabalho de Curso em Direito I e Trabalho de Curso em Direito II. Integrante do Núcleo Docente Estruturante e do Conselho do Curso de Administração da ULBRA Carazinho, também atua como docente nas disciplinas de Administração Pública, Gestão Tributária e Processo Decisório.

${ }^{2}$ Doutor em Ciências Humanas pela Universidade Federal de Santa Catarina - UFSC (2011); mestre em Direito Público pela Universidade do Vale do Rio dos Sinos - UNISINOS (2007); graduado em Direito pela Universidade de Santa Cruz do Sul - UNISC (2004). Professor Adjunto no Departamento de Direito da Universidade Federal de Santa Maria - UFSM. Professor do Programa de Pós-Graduação em Direito (PPGD/UFSM) - Mestrado em Direito. Professor do Programa de Pós-Graduação em Tecnologias Educacionais em Rede (PPGTER/UFSM) Mestrado Profissional em Tecnologias Educacionais em Rede. Pesquisador e Vice-Líder do Grupo de Pesquisa em Direito da Sociobiodiversidade - GPDS. Atualmente é Coordenador de Planejamento Acadêmico da PróReitoria de Graduação da UFSM. Desenvolve pesquisas nas áreas de: Direito Ambiental; Ecologia Política; Direito e Sustentabilidade; Direito Urbanístico; Teoria do Direito e da Decisão Jurídica; Direito e NovasTecnologias; Tecnologias Educacionais em Rede.
}

Revista de Direito Ambiental e Socioambientalismo | e-ISSN: 2525-9628 | Brasília | v. 3 | n. 1 | p. 1 - 19 | Jan/Jun. 2017. 
intergeracional consegue refrear o processo de degradação ambiental a fim de concretizar o acesso ao meio ambiente sadio e equilibrado para as gerações presentes e futuras.

Palavras chave: Sociedade Global de Risco. Constitucionalização. Princípio da Equidade Intergeracional

\title{
THE GLOBAL RISK SOCIETY AND THE CONSTITUTIONALIZATION OF THE PRINCIPLE OF INTERGENERATIONAL EQUITY
}

\begin{abstract}
The article aims to provide a projection on the process of constitutionalization of the principle of intergenerational equity to consolidate access to the healthy and balanced environment for present and future generations within the global risk society. The research uses the deductive method aided by dialectical premises to materialize a diagnosis about the proposed problem. In a first moment, it will be analyzed how industrial-capitalist modernity contributes in the process of constructing the global society of risk through the development of the techniquescience and its unfolding in the process of the degradation of the natural. Subsequently, it will be verified if the constitutionalisation of the intergenerational equity precept can restrain the environmental degradation process in order to materialize the access to the healthy and balanced environment for present and future generations.
\end{abstract}

Keywords: Global Society of Risk. Constitutionalisation. Principle of Intergrational Equity.

\section{INTRODUÇÃO}

O artigo realiza uma projeção sobre o processo de constitucionalização do princípio da equidade intergeracional, uma vez que a modernidade industrial-capitalista atrelada ao desenvolvimento industrial acelerado por meio do uso indiscriminado da técnica-ciência produz uma sociedade global de risco que gera incerteza sobre o futuro devido a manipulação do natural. Sob essa conjectura contemporâneo, a constitucionalização do princípio da equidade intergeracional teria condições de contribui com processo de consolidação dos direitos individuais/coletivos de acesso equânime ao meio ambiente sadio e equilibrado para as gerações presentes e futuras.

No aspecto metodológico a pesquisa se utiliza do método dedutivo para abordar se a incorporação do preceito da equidade intergeracional assegura a materialização dos direitos individuais/coletivos de acesso equânime ao meio ambiente sadio e equilibrado para as gerações presentes e futuras na sociedade global de risco. A pesquisa faz uso de premissas 
dialéticas a fim de corroborar com o processo de pesquisa no intuito de elucidar a problemática proposta.

Primeiramente, verificar-se-á como a modernidade industrial-capitalista deflagra/agrava a desigualdade social entre os indivíduos, em especial, a desigualdade econômica. Diante deste cenário, tem início o processo de construção da sociedade global de risco a partir do desenvolvimento industrial vinculado ao aprimoramento da técnica-ciência. Sob essa nova conjectura social, é perceptível que o uso indiscriminado da técnica-ciência acarreta a incerteza, uma vez que esta passa a ser amplamente utilizada para a confecção de "novos" insumos/produtos para atender a lógica economicista através de um processo de predação/exaurimento dos recursos naturais comprometendo o direito ao acesso equânime individual/coletivo ao meio ambiente sadio e equilibrado para as gerações presentes e futuras.

Posteriormente, determinar-se-á o impacto da constitucionalização do preceito da equidade intergeracional no processo de supressão/refreamento da utilização indiscriminada de recurso naturais para manter a candência produtiva da modernidade industrial-capitalista. É necessário pontuar também a atuação do preceito da equidade intergeracional no combate aos efeitos produzidos pela desigualdade social econômica e nos desdobramentos provocados pelos riscos/incertezas produzidos pelo uso indiscriminado da técnica-ciência na sociedade global de risco. A constitucionalização do princípio da equidade intergeracional tem a premissa de assegurar que o Estado e a sociedade construam mecanismo político-jurídicos com base, na solidariedade e comprometimento entre as gerações, para assim, garantir a manutenção do acesso/uso equitativo dos recursos naturais para as gerações presentes e futuras.

2. Os efeitos colaterais da sociedade global de risco: anúncios sobre o prelúdio da desigualdade social e sua conexão com a crise ambiental

A modernidade propicia a construção de um novo mundo que rompe com o modo de vida tradicional dos indivíduos por meio da industrialização deflagrada pelo capitalismo. Sob a égide desta conjetura, é possível vislumbrar que "os modos de vida produzidos pela modernidade nos desvencilharam de todos os tipos tradicionais de ordem social, de uma maneira que não têm precedentes." (GIDDENS, 1991, p. 10). O desvencilhamento do modo 
de vida "tradicional" acarreta uma inúmera gama de fenômenos sociais que tem impacto direito no processo de precarização das condições de vida dos sujeitos no âmbito local/global.

A modernidade se conecta a dimensão desse novo mundo industrializado. Sob esse contexto, as relações sociais são predeterminadas pela utilização generalizada da força material e do maquinário com o objetivo gerar forma nos processos de produção. A dimensão do capital coaduna junto aos sistemas de produção de mercadorias para assim abarcar os mercados competitivos de produtos e a mercantilização da força de trabalho do indivíduo. A fusão destas duas dimensões predetermina a gênese de um novo modelo de vida social inserido no contexto de modernidade instaurada pelo capitalismo-industrial. (GIDDENS, 2002)

A formação do padrão de individualismo contemporâneo está intimamente ligada a conjunção do capitalismo-industrial. O sujeito moderno passa a ser submetido por um processo de alienação originário do desdobramento dos fenômenos produzidos pelo capitalismo-industrial, e têm como consequência mais nefasta uma substancial/gradual diminuição dos direitos e/ou garantias fundamentais dos sujeitos tanto na esfera local/global, haja vista que a Soberania dos Estados se liquefaz frente essa nova ordem mundial.

A Soberania dos Estados se esvai, juntamente com a estrutura institucional/burocrática estatal contemporânea que percorre esse mesmo caminho tortuoso, pois resta demonstrada a incapacidade/fragilidade de ambos - Estado e estrutura institucional/burocrática - para a formulação de novas alternativas/iniciativas com o desígnio de assegurar/materializar, mesmo que de forma mínima, os direitos e/ou garantias fundamentais dos sujeitos tanto na esfera local ou global.

A hegemonia do sistema capitalista-industrial deflagrou um aumento exponencial da desigualdade social entre os sujeitos. A junção do processo de globalização econômica vinculada à incorporação de novas tecnologias no modo de vida dos sujeitos numa escala local/global durante a construção da modernidade capitalista-industrial contribuíram para o aumento da instabilidade econômica, que corrobora na formação/manutenção/propagação do fenômeno da desigualdade social, haja vista que a globalização "estaria destruindo culturas locais, ampliando desigualdades mundiais e piorando a sorte dos empobrecidos." (GIDDENS, 1991, p. 25) 
A convergência de todos estes fenômenos, com foco, na desigualdade econômica acaba por impulsionar a formação/consolidação de uma sociedade global de risco, pois "na modernidade tardia, a produção da riqueza é acompanhada sistematicamente pela produção social de riscos." (BECK, 2011, p. 23). Sob essa conjectura, o risco passa a ser disseminado de maneira (des)igual entre os sujeitos, haja vista que a desigualdade social na modernidade está condicionada a lógica do capital, ou seja, da distribuição da riqueza na sociedade contemporânea.

A distribuição do risco está vinculada a propagação da desigualdade social que tem sua gênese em determinadas fases do processo de modernização tardia. O processo de desenvolvimento industrial-tecnológico oriundo da modernidade acaba por transforma a estrutura da própria modernidade - modernidade reflexiva - que acarreta na formação de uma sociedade de risco. A sociedade global de risco produz ameaças e efeitos próprios aquém da vontade/controle dos indivíduos e acaba por corroer os alicerces da própria modernidade capitalista-industrial da qual se origina. (BECK, 2011)

A ambivalência no processo de automação industrial assume seu ápice dentro da modernidade reflexiva e acaba por influenciar na processo de composição social contemporânea, processo este que altera a percepção dos indivíduos sobre a realidade que os cerca, uma vez que o uso das "[...] tecnologias tem sido alçada de sua condição de meio para preencher necessidades humanas à finalidade e objetivos da aspiração humana.” (SANTOS, L., 2011, p.74)

A automação industrial floresce junto ao desenvolvimento técnico-científica, na conjectura deste cenário decorre um "aumento" do bem-estar social dos indivíduos, uma vez que os "novos" produtos/insumos/serviços tende a saciar um mercado consumidor ávido por "novidades". Sob esse pretexto, o homem atua com mais tenacidade nas técnicas prospecção/exploração/extração dos recursos naturais para atender os anseios do mercado de consumo, essa postura acarreta um aumento exponencial da degradação/exaurimento dos recursos naturais, e corrobora na construção de uma crise ecológica de proporções globais.

A crise ecológica advinda da modernidade capitalista-industrial tem sua origem nos efeitos colaterais impingidos pelo desenvolvimento industrial acelerado combinado com a imprevisibilidade na manipulação da técnica-ciência empregada para a produção de "novos" 
produtos/insumos/serviços. A sociedade industrial-capitalista produz efeitos nefastos junto ao natural, uma vez que a prospecção/degradação/predação dos recursos naturais jaz sob uma aura de naturalidade/distância da percepção da maioria dos indivíduos.

O império da incerteza opera na sociedade global de risco. A incerteza esta condicionada ao crescimento acelerado da técnica-industrial. As novas interações sociais impostas pela sociedade global de risco determinam uma autorreflexão sob esse processo de interação a fim de reexaminar os conceitos fundamentais que dão suporte a racionalidade moderna. Frente as consequências impingidas pela sociedade global de risco se torna necessária a consciência de uma autodeterminação reflexiva diante do novo contexto social contemporâneo. (BECK; GIDDENS; LASH, 1997)

A incerteza social, na sociedade global de risco, transforma a percepção dos conflitos na contemporaneidade. Estes conflitos passam a ser valorados de forma diferenciada, pois não estão mais no patamar dos problemas de ordem, mas passam a se configuram como problemas de risco. A autoimagem da sociedade global de risco, determina a sua reflexividade social, ou seja, a sociedade se torna um tema e um problema para ela própria. (BECK, 2011) Por outro lado, as incertezas produzidas podem conduzir à uma especulação do medo na sociedade global "transformando-o na base de uma política de controle e repressão (BAUMAN, 2009, p.9).

A sociedade global de risco figura sob três categorias distintas, na primeira categoria figura o risco e a catástrofe, a segunda categoria é constituída pelo risco e a valoração da cultura do risco, e por fim figura a categoria das três lógicas do risco global. A amálgama destas categorias fomenta o questionamento das idéias centrais para a construção do contrato de risco e ventila a possibilidade do controle do risco por meio da probabilidade de compensação das incertezas/perigos que são fabricados industrialmente. (BECK, 2011)

A condição da existência humana é afetada por inúmeras ameaças/incertezas que irrompem no decorrer da ação da modernização industrial-capitalista subordinada a ampliação tecnológica. O risco se consolida nestas condições, e se desdobra em inúmeros mecanismos para estender/influenciar diretamente as categorias das decisões/incertezas/probabilidades que estão condicionadas com um risco futuro - riscos transtemporais - que ainda não pode ser 
avaliado, haja vista que os danos ocasionados por estes eventos estão envoltos numa áurea de anfibologias. (BECK, 2011)

O risco passa a ser incorporado pela condição humana, tal condição provoca um novo olhar acerca do modo de (re)pensar a ciência, a política e a economia, haja vista que o risco é distribuído sob um panorama "democrático", mas sempre condicionado numa incerteza futura - riscos transtemporais. Os riscos na modernização capitalista-industrial comprometem todos os indivíduos, mas diante da sua lógica distributiva acaba por atingir num primeiro momento os indivíduos em situação de vulnerabilidade econômica. (BECK, 2011)

O risco toma forma através da construção de eventos/ações no espaço-tempo futuros, ou seja, o risco se materializa através da incerteza que se produz no campo das nossas expectativas/ações, com foco, nas incertezas produzidas no campo político. O risco consiste na antecipação da catástrofe. O campo político se tornou o palco de debate onde os conflitos que provocam riscos operam, uma vez que as pautas que ocasionam os problemas ligados a produção do risco na sociedade contemporânea são amplamente divulgadas/debatidas numa perspectiva "democrática", mas decididas a portas fechadas. O déficit democrático tem contribuído na construção desta lógica perversa. (BECK, 2011)

A modernização industrial-capitalista por meio da ampliação técnico-econômico facilitou a aceleração/formação de uma sociedade global de risco onde a projeção do risco se torna mais difícil de ser detectada devido a intima conexão entre técnica e ciência. A evolução da técnica-cientifica constrói uma sociedade que não consegue perceber/controlar a produção dos riscos futuros - transtemporais - que acabam por se consumarem como irreversíveis depois de revelados.

A biotecnologia consente ao homem acesso a técnica-ciência para criar/manipular/dominar o natural. Esse contexto permite que a biotecnologia se transforme numa ferramenta sofisticada para corroborar no artifício de subjugar a biodiversidade aos interesses do mercado econômico. (SANTOS, L., 2011, p. 24). As empresas transnacionais privadas têm se servido do desenvolvimento dentro da área biotecnológica para posterior aplicação no setor industrial a fim de conduzir/centralizar/privatizar o monopólio pelo controle do conhecimento nos setores industriais primários, secundários e terciários por meio de produtos/insumos. 
O risco da utilização desses produtos/insumos concebidos biotecnologicamente é exportado para os países em desenvolvimento, haja vista que as leis/regulamentações tende a ser relativizadas por estes Estados frente ao poder econômico dessas empresas transnacionais privadas. Essa tática é amplamente utilizada por essas empresas multinacionais para burlar a leis/regulamentações onde a construção desse arquétipo acarreta uma instabilidade/dependência nas esferas sociais, econômicas e ecológicas dos países do Sul que “consomem" tais produtos biotecnológicos.

O emprego dos produtos/insumos de origem biotecnológica na fabricação de bens de consumo, em especial, pelas áreas alimentar, cosmética e farmacêutica acarreta um significativo aumento do risco de danos ecológicos e a precarização da saúde humana. A preocupação com o aumento da problemática na esfera ecológica e da saúde humana ocorre devida "a ignorância sobre os impactos das novas tecnologias sobre o meio ambiente e a saúde humana é maior que o conhecimento necessário a sua produção.” (SHIVA, 2003, p. 129).

Sob essa perspectiva, Morin (2000) alerta que a ideia de progresso é permeada pela noção de melhorias em várias esferas da condição humana. Contudo, o autor adverte que o desenvolvimento - muitas vezes linear - ocasionado pelo progresso pode gerar subprodutos nocivos a condição humana, e não raras vezes, esses subprodutos assumem o papel de protagonistas afetando nocivamente a natureza e a condição humana.

O conhecimento técnico/científico desenvolveu inúmeros avanços decorrentes do processo de industrialização. Não obstante, o acúmulo desse conhecimento paradoxalmente aumentou as incertezas, uma vez, que conforme ocorre o aprimoramento do conhecimento técnica-cientifica vinculada a uma matriz epistemológica comprometida com reducionismo geometrizado nos afasta das origens míticas da criação, as respostas não estão mais entre nós, e se afastam cada vez mais.

Nesse ínterim, urge a necessidade de compreender o processo de modernização capitalista-industrial, com ênfase, na globalização econômica e seus desdobramentos na construção de uma sociedade global de consumo. O padrão de crescimento econômico voltado ao desenvolvimento industrial acelerado impacta diretamente sobre o processo de exaurimento dos recursos naturais não renováveis do planeta, haja vista que "a globalização 
não está se desenvolvendo de uma maneira equitativa, e está longe de ser inteiramente benéfica em suas consequências." (GIDDENS, 1991, p. 25)

Sob essa premissa, é latente a necessidade dos países não-hegemônicos aprimorarem os seus respectivos mecanismos estatais para controlar/avaliar nas esferas ecológica/econômica/social as consequências advindas da utilização indiscriminada de recursos naturais para a confecção de insumos/produtos utilizados para abastecer o mercado de consumo. Essa postura, é necessária para assegurar/resguardar a integridade do patrimônio ecológico para uso/aceso equitativo para as gerações presentes e futuras.

3. A constitucionalização do princípio da equidade intergeracional: uma projeção sobre a concretização do acesso ao meio ambiente sadio e equilibrado para as gerações presentes e futuras

É possível perceber que a crise ambiental contemporânea perpassa o referencial ecológico clássico, ela é multifacetada, o pensamento dominante apregoa que esta crise se instaura apenas pelo uso excessivo dos recursos naturais para a manutenção da cadência do crescimento industrial. Nesse panorama, brota o princípio da equidade intergeracional, com a premissa de nortear as legislações internacionais/nacionais, na construção de mecanismos político-jurídicos que concretizem o acesso equitativo aos recursos naturais para as gerações presentes e gerações futuras.

Sob esse ponto de vista, em 1972, a ONU realiza a Conferência de Estocolmo, a fim de debater alternativas para os principiais problemas ambientais modernos. A Conferência de Estocolmo figura como um marco ecológico de dimensão global, haja vista que a mesma será responsável pela consagração de princípios que tem a premissa de resguardar o acesso ao Meio Ambiente Humano a partir de uma perspectiva socioeconômica no intuito de refrear o modelo de desenvolvimento predatório para o natural imposto pela modernidade industrialcapitalista. (MILARÉ, 2005)

A Conferência de Estocolmo traz em seu bojo o preceito da equidade intergeracional, o dispositivo em tela determina como questão fundamental a proteção/melhoria do meio ambiente com o intuito de assegurar o bem-estar dos povos e um desenvolvimento econômico 
global sustentável. A materialização do preceito da equidade intergeracional figura como dever do Estado e da sociedade a partir da elaboração de mecanismos político-jurídicos com o objetivo de garantir o acesso a um meio ambiente sadio e equilibrado para as gerações presentes e gerações futuras.

A prospecção indiscriminada de recursos naturais com o intuito de garantir o ritmo do desenvolvimento econômico/industrial acaba por comprometer o processo de regeneração do natural. O modelo econômico de matriz neoliberal tenta impedir o alastramento da degradação ambiental por meio da "modernização ecológica". Contudo, a "modernização ecológica" tende a ignorar os efeitos ocasionados pela desigualdade social no processo de degradação do natural, uma vez que a agenda da "modernização ecológica" tem o compromisso de conciliar o interesse do crescimento econômico a resolução da problemática ambiental através do uso de tecnologia. (ACSELRAD; MELLO, BEZERRA, 2009)

Para fazer frete a esta conjectura e tentar assegurar a preservação do acesso ao patrimônio ecológico para as gerações presentes e futuras, em 1997, a UNESCO, promulga a Declaração sobre as Responsabilidades das Gerações Presentes as Gerações Futuras na tentativa de abrandar a postura predatória do homem na prospecção dos recursos naturais para manter o ritmo de desenvolvimento industrial. A pretensa declaração evoca em seu Art. $5^{\circ}$ e respectivos incisos a proteção/tutela do acesso ao meio ambiente saudável e equilibrado para as gerações presentes e futuras.

Sob essa conjectura, o Estado tem o dever criar mecanismos eficazes para realizar o combate à desigualdade social de viés econômico, por meio da implementação de políticas públicas que certifiquem uma melhor distribuição de renda para a abrandar o abismo social entre os indivíduos. A construção de um novo regime de justiça social passa inexoravelmente pela reformulação do aparato jurídico estatal com vistas a propiciar meios materiais, por intermédio de ações político-jurídicas para certificar que os indivíduos possam ter acesso a uma existência digna através do combate às desigualdades sociais, com foco, na miséria, pois a "justiça social só se realiza mediante equitativa distribuição de riqueza." (SILVA, 2013, p. 721)

O Estado necessita avançar no processo de materialização dos direitos e/ou garantias ambientais que tangenciam a uso/acesso aos recursos naturais paras as gerações presentes e 
futuras, pois é necessário “impor limites ao mercado, por meio da participação do Estado, ou colocar limites em sua lógica." (LEITE, 2003, p. 189). É preciso (re)pensar o direito tradicional, haja vista que os "novos direitos" e a complexidade das relações sociais , aliada a morosidade do aparato jurídico estatal, torna fundamental pensar em novos mecanismos de resolução de conflitos que envolvam assegurar o uso/acesso equitativo dos recursos naturais para as gerações presente e futuras.

Entretanto, o padrão jurídico ambiental contemporâneo está comprometido com um padrão exegético que não consegue acompanhar os problemas oriundos de uma sociedade complexa. Sob essa premissa, o padrão jurídico ambiental contemporâneo precisa se realinhar para atender as necessidades contemporâneas de proteção/tutela dos recursos naturais, haja vista que "tutela, predominantemente um interesse ou direito difuso, indivisível, de natureza meta-individual e indeterminável quanto ao sujeito, indisponível no que tange o seu objeto, que propugna por uma ação solidária.” (LEITE, 2003, p. 25)

Resta demonstrada à latente inquietação que paira sobre as interações entre o homem e o natural, isso figura na preocupação dos Estados em concretizar estruturas constitucionais para abrigar a tutela coletiva dos sujeitos na proteção/direito ao meio ambiente saudável e equilibrado, com foco, no acesso/uso equitativo aos recursos naturais pelas gerações presentes e futuras. Os princípios constitucionais de ordem ambiental têm atuado como elementos estruturantes no Estado Democrático de Direito, e são a amálgama do sistema políticojurídicos na nova conjectura socioambiental, uma vez que "o princípio da sustentabilidade é um princípio aberto carecido de concretização conformadora e que não transporta soluções prontas, vivendo de ponderações e de decisões problemáticas.” (CANOTILHO, 2010, p. 08)

O fenômeno da constitucionalização ambiental figura como alternativa para assegurar a eficácia/materialização dos preceitos consagrados em nossa Carta Magna. O princípio da sustentabilidade se reveste de um caráter estruturante, corporatura como um "imperativo categórico coletivo" onde se impõe um método de (re)organização das condutas/ações do ser humano no combate/refreamento no processo de predação do natural por meio de estruturas político-jurídicos que assegurem o uso/acesso equitativo dos recursos naturais para as gerações presentes e futuras. (CANOTILHO, 2010) 
O princípio da sustentabilidade se ampara em três categorias distintas interconectadas, a primeira categoria esta representada pelo preceito da sustentabilidade interestatal vinculada com a injunção de uma equidade entre países desenvolvidos e em desenvolvimento; a segunda categoria abarca a sustentabilidade geracional e visa concretizar o preceito da equidade entre indivíduos que pertencem a mesma geração, mas de faixa etárias diversas, e a terceira categoria figura a sustentabilidade intergeracional responsável pela imposição da equidade entre as gerações presentes e futuras. (CANOTILHO, 2010). O princípio da sustentabilidade visa realizar o rompimento sob o olhar da problemática ambiental adotado pelo direito tradicional, ao determinar que a sustentabilidade "[...] consiste em assegurar, de forma inédita, as condições propicias ao bem-estar físico e psíquico no presente, sem empobrecer e inviabilizar o bem-estar no amanhã." (VEIGA, 2012, p. 15)

Sob essa perspectiva, a Constituição Federal de 88, por meio dos seus princípios fundamentais, tenta irradiar um conjunto de valores para nortear as ações do Estado acerca da coletividade nas esferas política/jurídica/econômica. Nesse contexto, o Estado engloba as condutas/decisões sobre o uso/acesso equânime dos recursos naturais na esfera individual/coletiva. O Estado deve adotar a postura de mediador dos interesses dos indivíduos e da coletividade, haja vista que a "característica de solidariedade, pois visa à proteção jurídica de um bem autônomo pertencente a toda a coletividade de forma mancomunada." (LEITE, 2003, p. 183)

As normas constitucionais avocam o papel de ator principal dentro do sistema jurídico tradicional para orientar a construção de uma teoria geral do direito comprometida com o reconhecimento e a efetivação de uma gama de "novos direitos" frutos da contemporaneidade, com foco, nos direitos ambientais e suas respectivas interconexões com o preceito da sustentabilidade intergeracional. As normas constitucionais concatenam uma evolução na tutela/materialização nesse rol de direitos, em especial, dos "novos direito" por meio articulação para a "[...] defesa coletiva do meio ambiente, consumidor, criança e adolescente, aposentado etc. há décadas atrás significaria abordar temas que não faziam parte real do mundo jurídico e muito menos do direito processual.” (LEITE, 2003, p. 28)

A jurisdição ambiental contemporânea abrange categorias essenciais para a formulação de uma eficácia na tutela do natural. A categoria garantístico-defensiva tem a 
premissa de assegurar uma defesa contra possíveis danos ambientais provocados pela interferência/influência do Estado e sua estrutura burocrática/institucional. Já, a categoria positivo-prestacional determina a obrigação estatal/institucional na criação de uma estrutura político-jurídicos para materializar a proteção/tutela do natural. A categórica jurídica irradiante submete obrigações ambientais as entidades privadas a fim de atender a coletividade. E por derradeiro, a categoria jurídica participativa que implica na concepção de estruturas para regular a obrigação da proteção ambiental pelos indivíduos e sociedade civil. (CANOTILHO, 2010)

A Constituição Federal de 1988 é contagiada, na esfera socioambiental, pelos preceitos da Conferência de Estocolmo, haja vista que ocorre o cooptação de vários princípios para nortear a tutela/proteção do meio ambiente. O Art. $3^{\circ}$ da Constituição Federal de 1988, que estabelece os objetivos fundamentais da República Federativa do Brasil, elenca em seu inciso II, a "garantir o desenvolvimento nacional". A Carta Magna precípua no Art. 170, inciso IV, a "defesa do meio ambiente, inclusive mediante tratamento diferenciado conforme o impacto ambiental dos produtos e serviços e de seus processos de elaboração e prestação." (BRASIL, 2015)

Sob essa égide, a Constituição Federal de 1988, mais precisamente no caput do Art. 225 consagra o preceito da equidade intergeracional com o objetivo de criar condições para o florescimento de um Estado e a coletividade comprometidos com a materialização do direito ao meio ambiente ecologicamente equilibrado no intuito de assegurar à sadia qualidade de vida para as gerações presentes e gerações futuras. A junção dos referidos dispositivos constitucionais demonstra que o Estado deve primar pela construção de um modelo de desenvolvimento econômico comprometido com o princípio da sustentabilidade, com foco, na supressão das desigualdades sociais/econômicas com o intuito de refrear a degradação ambiental provocada pela miséria.

O preceito da sustentabilidade atua como princípio constitucional estruturante vinculado ao princípio da responsabilidade intergeracional, uma vez que visa realizar uma tutela que assegure a construção de um meio ambiente sadio e equilibrado para as gerações presentes e futuras. De outra banda, é necessário destacar que a codificação dos referidos preceitos não assegura a sua eficácia, pois “[...] se observa a veloz corrosão dos direitos e do 
Direito suscitada pela evolução econômica de um mundo globalizado, o que salta aos olhos é a impressão da inevitabilidade desse processo.” ( SANTOS, L., 2011, p. 229)

Para atingir tal intento, é necessário que o Estado efetive a criação de mecanismos político-jurídicos para refrear o processo de degradação ambiental com o intuito de afiançar o direito à existência das gerações futuras. $\mathrm{O}$ preceito da equidade intergeracional tem sua gênese na ânsia de articular um mecanismo político-jurídico comprometido com a tutela/garantia/necessidade de sujeitos indeterminados. Sob essa perspectiva à tutela/garantia desses sujeitos está condicionado a um futuro incerto, uma vez que estes sujeitos ainda não "existem" de fato.

Os dispositivos constitucionais inseridos em nossa Carta Magna passam a tutelar o meio ambiente. Contudo, é perceptível que o legislador tenta atrelar o desenvolvimento econômico e a livre iniciativa de mercado com vistas a resguardar o acesso aos recursos naturais por meio do desenvolvimento sustentável. É possível observar que a redação dos dispositivos constitucionais tenta assegurar a proteção do natural a partir do desenvolvimento sustentável. Entretanto, não preceitua sob qual aspecto se dará essa efetiva proteção. Os referidos dispositivos constitucionais ainda possuem o ranço característico do direito tradicional exegético vinculados a uma matriz neoliberal que atende aos interesses do mercado econômico.

Sob essa conjectura, o constitucionalismo ambiental traz esperança na atuação como marco regulatório tentar garantir o equilíbrio intergeracional por meio da tutela/proteção do acesso os recursos naturais para as gerações presentes e futuras. A transformação desta realidade inicia pela criação de mecanismos político-jurídicos eficazes com a atribuição de materializar os preceitos ecológicos, para assim assegurar uma qualidade de vida e a proteção ambiental necessária para o impedir a degradação do patrimônio ecológico e assegurar o seu uso/acesso equânime numa escala individual e coletiva.

As gerações presentes têm o dever/necessidade de conservar os recursos naturais essenciais para a construção/manutenção da vida para as gerações futuras, ou seja, devem restaurar os recursos naturais utilizados para a confecção de bens/produtos na mesma proporção de sua retirada a fim de não comprometer/exaurir os mesmos, para que desta forma 
as gerações futuras possam se beneficiar destes respectivos recursos naturais para a criação e manutenção do seu modo de vida

\section{CONSIDERAÇÕES FINAIS}

O artigo realizou uma projeção sobre a capacidade processo de constitucionalização do princípio da equidade intergeracional em suprimir/refrear a ação de predação do natural provocada na modernidade industrial-capitalista pelo aceleramento do desenvolvimento industrial ocasionado pelo emprego indiscriminado da técnica-ciência que teve por efeito colateral um amento exponencial da desigualdade social, com foco, na desigualdade econômica e na produção de uma sociedade global de risco que compromete o acesso aos recursos naturais para as gerações presente e as gerações futuras.

Nesta linha de ideias, é possível determinar que a modernidade industrial-capitalista através do desenvolvimento acelerado por meio da utilização/fusão da técnica-ciência deflagra um procedimento de manipulação/dominação do natural no sentido de produzir "novos" insumos/produtos para um mercado consumidor ávido por novidades. O desenrolar deste processo acarreta efeitos colaterais nefastos para a condição humana numa escala local/global.

Diante desta nova ordem global, é percebível o aumento exponencial da desigualdade social entre os indivíduos, em especial, os indivíduos em situação de vulnerabilidade econômica sofrem mais com a precarização das condições de vida. O Estado não consegue fazer frente a esse fenômeno, e segue a lógica economicista, eliminado/diminuindo o acesso do cidadão a direitos e/ou garantias fundamentais, uma vez que a lógica capitalista determina que o sujeito existe na medida em que consome.

Sob essa nova conjectura social de precarização, floresce a sociedade global de risco, onde o uso indiscriminado da técnica-ciência no desenvolvimento industrial acaba gerar o risco/incerteza. Os problemas que figuram na esfera do risco/incerteza são transtemporais, ou seja, suas consequências/impactos serão sentidos somente depois de desvelados, isso gera consequências/impactos na saúde humana e na área ambiental e compromete o direito ao acesso equânime individual/coletivo ao meio ambiente sadio e equilibrado para as gerações presentes e futuras. 
O princípio da equidade intergeracional ventilado na Conferência de Estocolmo, determina um rol de obrigações na tutela/proteção dos recursos naturais de forma equitativa. O preceito da equidade intergeracional determina a conexão entre a desigual social e a aceleração no processo de depredação do natural, tal constatação gera consequências no acesso equânime aos recursos naturais para as gerações presentes e futuras. Nesse sentido, é necessário que o Estado e a sociedade construam mecanismos jurídico-políticos para materializar a defesa do acesso ao meio ambiente sadio e equilibrado para as gerações presentes e as gerações futuras.

A constitucionalização do princípio da equidade intergeracional tem a premissa de assegurar que por meio da força do dispositivo constitucional que o Estado e a sociedade construam mecanismo político-jurídicos com base, na solidariedade e comprometimento entre as gerações, para assim, garantir a manutenção do acesso/uso equitativo dos recursos naturais para as gerações presentes e futuras com vistas a assegurar uma qualidade de vida e a proteção ambiental.

\section{Referencias}

ACSELRAD, Henri; MELLO, Cecília Campello do A.; BEZERRA, Gustavo das Neves. O que é justiça ambiental. Rio de Janeiro: Garamond, 2009.

BECK, Ulrich. Sociedade de risco: rumo a uma outra modernidade. São Paulo: Editora 34, 2011.

CANOTILHO, José Joaquim Gomes. O princípio da sustentabilidade como princípio estruturante do Direito Constitucional. In: Revista de Estudos Politênicos, 2010, Vol. VIII, n 13, 07 -18.

FREITAS, Juarez. Sustentabilidade: Direito ao Futuro. 2.ed. Belo Horizonte: Fórum, 2012.

GIDDENS, Anthony. O mundo em descontrole. Tradução de Maria Luiza X. de A. Borges. Rio de Janeiro: Record, 2007.

GIDDENS, Anthony. As consequências da modernidade. São Paulo: Editora UNESP, 1991.

MIRALÉ, Édis. Direito do ambiente: doutrina, jurisprudência, glossário. 4.ed. rev., atual. e ampl. São Paulo: Editora Revista dos Tribunais, 2005. 
MORIN, Edgar.. Ciência com consciência. Tradução de Maria de Alexandre e Maria Alice Sampaio Dória. 4.ed. Rio de Janeiro: Bertrand Brasil, 2000.

SANTOS, Laymert Garcia dos. Politizar as novas tecnologias: o impacto sociotécnico da informação digital e genética. 2.ed. São Paulo: Editora 34, 2011.

SILVA, José Afonso da. Curso de Direito Constitucional Positivo. 36.ed. rev. atual. São Paulo: Malheiros Editores Ltda, 2013.

SHIVA, Vandana. Monoculturas da mente: perspectivas da biodiversidade e da biotecnologia. São Paulo: Gaia, 2003.

>. Acessado em: 10 Nov. 2015. 